\title{
Emergency tips recanalisation and gastroesophageal varices embolisation with an ethylene vinyl alcohol copolymer agent (Squid) and detachable coils
}

Massimo Venturini ${ }^{1,2^{*}}$, Luigi Augello ${ }^{3}$, Carolina Lanza ${ }^{4}$, Marco Curti ${ }^{2}$, Andrea Coppola $^{2}$, Filippo Piacentino ${ }^{2}$ and Francesco De Cobelli $i^{3,5}$

\begin{abstract}
Transjugular intrahepatic portosystemic shunt (TIPS) is currently indicated as first therapeutic option in the main complications of portal hypertension, including bleeding gastroesophageal varices and refractory ascites. In case of bleeding gastroesophageal varices, an adjuvant embolisation within TIPS can be useful to prevent rebleeding. In the present technical note, the management in emergency of a patient with haemorrhagic shock due to bleeding gastroesophageal varices and occluded TIPS is reported. TIPS recanalisation with an adjunctive stent and high-pressure balloon angioplasty and gastroesophageal varices embolisation using detachable coils and a non-adhesive liquid embolic agent were performed during the same emergent procedure. After the procedure, clinical stabilisation of the patient was achieved, with blood transfusions suspension and Blakemore tube removal. At 6 months, regular TIPS patency at colour Doppler and no rebleeding episodes were recorded. To our knowledge, whilst coils are routinely used for varices embolisation, non-adhesive liquid embolic agents have been never mentioned. Liquid embolic agents seem to provide a stable plug strengthening the embolising action of the coils. Further studies involving a cohort of patients with long-term follow-up will be necessary to confirm whether this association can be more effective than coils alone in gastroesophageal varices embolisation.
\end{abstract}

Keywords: Embolization (therapeutic), Esophageal and gastric varices, Ethylene-vinyl alcohol copolymer, Hypertension (portal), Portosystemic shunt (transjugular intrahepatic)

\section{Key points}

- Bleeding gastroesophageal varices are a typical complication of portal hypertension usually requiring transjugular intrahepatic portosystemic shunt (TIPS) in election or in emergency.

- Non-adhesive liquid embolic agents as ethylenevinyl alcohol copolymers are routinely used in cerebral field, less often in abdominal district.

\footnotetext{
* Correspondence: massimo.venturini@insubria.it

'Department of Diagnostic and Interventional Radiology, Circolo Hospital, Viale Borri 57, 21100 Varese, Italy

${ }^{2}$ Insubria University, Varese, Italy

Full list of author information is available at the end of the article
}

- Coil embolisation of bleeding gastroesophageal varices during the TIPS placement or in case of occluded TIPS is a possible adjunctive procedure.

- The use of a non-adhesive liquid embolic agent associated with coils can potentially strengthen the embolic action probably allowing a more permanent occlusion of gastroesophageal varices than coils alone.

\section{Background}

Portal hypertension remains the main complications of cirrhosis. Transjugular intrahepatic portosystemic shunt (TIPS) represents the main therapeutic option in case of refractory ascites and bleeding from gastroesophageal

\section{Springer Open}

(c) The Author(s). 2020 Open Access This article is licensed under a Creative Commons Attribution 4.0 International License, which permits use, sharing, adaptation, distribution and reproduction in any medium or format, as long as you give appropriate credit to the original author(s) and the source, provide a link to the Creative Commons licence, and indicate if changes were made. The images or other third party material in this article are included in the article's Creative Commons licence, unless indicated otherwise in a credit line to the material. If material is not included in the article's Creative Commons licence and your intended use is not permitted by statutory regulation or exceeds the permitted use, you will need to obtain permission directly from the copyright holder. To view a copy of this licence, visit http://creativecommons.org/licenses/by/4.0/. 
varices, in particular when medical or endoscopic treatments fail $[1,2]$.

An adjuvant embolisation of gastroesophageal varices within TIPS procedure can be useful to prevent a rebleeding. Coil embolisation is routinely used, although alternative embolic agents or devices, such as glue or plugs [3-5], were also used in gastroesophageal varices embolisation. Advantages of detachable coils, nowadays less expensive than in the past, are their marked radiopacity and their capability to be removed and replaced when necessary, whilst their major limit is the achievement of a complete and permanent occlusion [6]. Non-adhesive, ethylene-vinyl alcohol $(\mathrm{EVOH})$ liquid embolic agents mixed with micronised tantalum powder and dissolved in dimethyl sulfoxide (DMSO), as Onyx and Squid, were mainly used in the cerebral district $[7,8]$. However, they have recently also used in abdominal diseases, alone as in endoleak embolisation [9, 10] or associated with coils for treating splenic [11] or renal aneurysms [12]. Squid, more recently introduced than Onyx, associated with coils seems to provide a more stable and totally occlusive cast to prevent recanalisation. In the present technical note, an emergency TIPS recanalisation with bleeding gastroesophageal varices embolisation using Squid and detachable coils is presented.

\section{Case report}

The management of a 58-year-old man with post-hepatitis $\mathrm{C}$ advanced cirrhosis, mild ascites and massive haematemesis come to the emergency department of our hospital is referred. The patient presented in our emergency department with massive haematemesis, hypotension (blood pressure $90 / 60 \mathrm{mmHg}$ ), tachycardia (110 beats per minute) and anaemia (haemoglobin level $9 \mathrm{mg} / \mathrm{dL}$ ). Haemodynamic instability of the patient was treated by blood transfusions and by Blakemore tube placement in the stomach. An emergency contrast-enhanced computed tomography (CT) showed large gastroesophageal varices and an occluded TIPS (Fig. 1a) placed 3 years ago at another hospital. A TIPS recanalisation with gastroesophageal varices embolisation was planned in emergency setting. The hemodynamically stabilised patient signed a specific institutional procedure-related consent form that covers retrospective observational studies. The procedure was performed by an experienced ( $>20$ years) interventional radiologist (M.V.) during patient conscious sedation.

After the placement of a 7-F introducer in the right jugular vein, the occluded TIPS was crossed using a 0.035in. hydrophilic guidewire (Terumo, Tokyo, Japan) and a 4F Headhunter catheter (Cordis, Miami Lakes, FL, USA). Portal pressure was $36 \mathrm{mmHg}$. The preliminary portography showed large gastroesophageal varices (Fig. 1b). First gastric varices (Fig. 1c), then oesophageal varices (Fig. 1d) were catheterised with a coaxial microcatheter (1.9 Carnelian, Tokai, Sarayashiki Taraga Kasugay City, Japan) and progressively embolised with detachable coils $(18-20-\mathrm{mm}$ diameter, 30-50-cm length; Interlock, Boston Scientific Corporation, Marlborough, MA, USA) and an (EVOH) copolymer agent (Squid-Peri 34, Emboflu, Gland, Switzerland). EVOH liquid embolic agent was shacked for 15-20 min and, before administration, the microcatheter dead space was filled with DMSO. Squid was then slowly injected to minimise DMSO-related pain due to its endothelial toxicity, progressively retracting the microcatheter to avoid its entrapment. No pain was recorded during Squid administration. After gastroesophageal varices embolisation, a self-expandable bare metal stent $(12 \mathrm{~mm}$ diameter, $8 \mathrm{~cm}$ length; Wallstent, Boston Scientific Corporation, Marlborough, MA, USA) was overlapped to the previous stent and finally a balloon-angioplasty $(10 \mathrm{~mm}$ diameter, $4 \mathrm{~cm}$ length, $18 \mathrm{~atm}$ insufflation pressure) of the whole TIPS was performed (Fig. 1e). Portal pressure at the end of the procedure was $24 \mathrm{mmHg}$. The final portography showed a quick opacification of the TIPS and the right atrium without gastroesophageal varices evidence, as good function of the portosystemic shunt (Fig. 1f). Contrast material administered during the procedure was about $60 \mathrm{~mL}$ of Iopromide (Ultravist 370, Bayer HealthCare, Berlin, Germany). After the procedure, clinical stabilisation of the patient was achieved, blood transfusions were suspended and Blakemore tube was removed. At discharge 6 days after the procedure, haemoglobin level was $11.4 \mathrm{mg} / \mathrm{dL}$. No rebleeding episodes were recorded during 6 months of follow-up. Colour Doppler ultrasound at $24 \mathrm{~h}$ and at 1 and 6 months confirmed the TIPS patency.

\section{Discussion}

Venous embolisation with an EVOH liquid embolic agent associated with $n$-butyl-cyanoacrylate was previously described for occlusion of portal branches in preoperative portal vein embolisation [13]. Squid use as embolic agent in various abdominal diseases [10] and its association with detachable coils in visceral artery aneurysms were recently reported [11, 12]. In the present case, detachable coils were first placed to provide the scaffold, subsequently compacted by Squid 34, the most viscous formulation, achieving a stable and occlusive plug. EVOH liquid embolic agent can strengthen the embolising power of the coils. The two best known non-adhesive EVOH liquid embolic agents are Onyx and Squid, both available in different formulations characterised by variable viscosity. They are similar but Squid, marketed more recently, is also available in the less viscous formulation which spreads more distally and may be useful in selected cases, as for example to treat arteriovenous malformations $[8,14]$. Another advantage of Squid over Onyx is the reduced percentage (less 30\%) and smaller size of tantalum particles conditioning fewer metallic artefacts on CT images $[15,16]$. Compared to adhesive liquid embolic agents as glue, Squid and Onyx are more expensive 

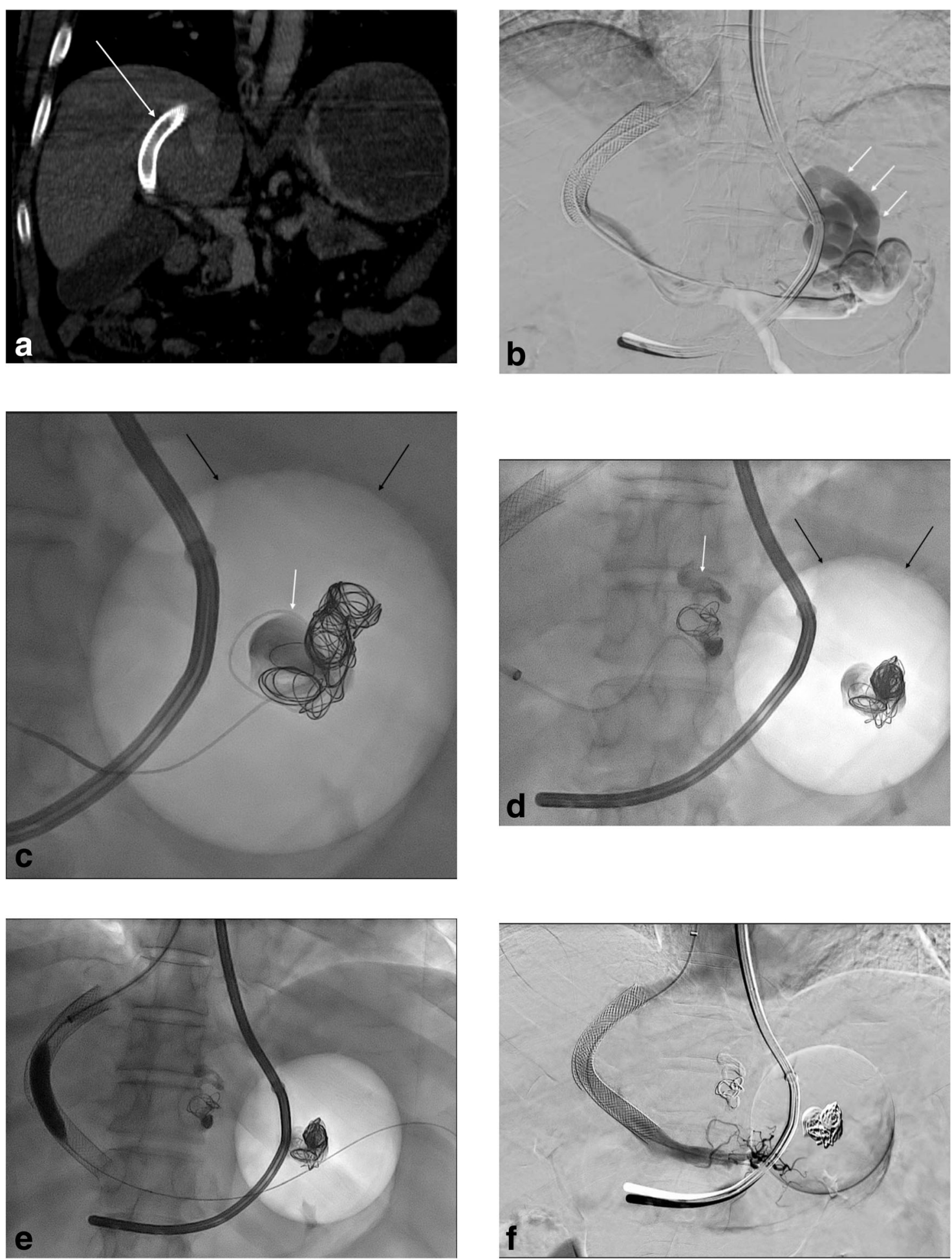

Fig. 1 a Contrast-enhanced computed tomography in emergency in a cirrhotic patient with haematemesis shows an occluded transjugular intrahepatic portosystemic shunt (TIPS) (white arrow). b Portography after TIPS recanalisation shows large gastric varices (white arrows). c Embolisation with an ethylene-vinyl alcohol (EVOH) liquid embolic agent (white arrow) and detachable coils of the gastric varices through a coaxial microcatheter. A Blakemore tube with inflated balloon in the stomach is evident (black arrows). d After gastric varices embolisation in the projective correspondence of the Blakemore tube (black arrows), also oesophageal varices were embolised with liquid embolic agent (white arrow) and detachable coils. e After gastroesophageal varices embolisation and an overlapped second stent placement, TIPS recanalisation was completed with high-pressure balloon angioplasty. f Final portography shows a quick opacification of the TIPS and the right atrium as good function of the portosystemic shunt without more evidence of the gastroesophageal varices 
but can provide a more predictable formulation-dependent distribution, resulting in more homogeneous casts. Moreover, the risk of accidental complications due to non-target vessel embolisation is probably higher using glue than EVOH embolic agents: glue spreads in a flow-dependent manner and can potentially be displaced during microcatheter retraction, if stuck to its tip [17]. This risk can increase in case of a retraction of a microcatheter for a long distance without the protection of a standard angiographic catheter as for example in the case of a type 2 endoleak embolisation performed through the Riolano arch [18]. A disadvantage of non-adhesive liquid embolic agents is the need of DMSO, potentially endotheliotoxic and unnecessary using glue.

Before Squid infusion, DMSO (not radiopaque) was slowly injected to minimise the possible pain due to its endothelial toxicity. Usually, in case of DMSO infusion in a large vascular bed, such as gastroesophageal varices, procedures are well tolerated without need for pain medication [19], as in our case. After gastroesophageal varices embolisation, TIPS was prolonged in portal vein with a second bare metal stent overlapped with the first previously placed stent and finally a high-pressure balloon angioplasty was performed.

Summarising, in our preliminary experience, simultaneous TIPS recanalisation and gastroesophageal embolisation with an EVOH liquid embolic agent and coils was successfully performed in emergency, with good clinical mid-term outcome. Further studies involving cohorts of patients with long-term follow-up are needed to validate the association of EVOH liquid embolic agents and coils in gastroesophageal varices embolisation.

\section{Abbreviations}

CT: Computed tomography; DMSO: Dimethyl sulfoxide; EVOH: Ethylene-vinyl alcohol; TIPS: Transjugular intrahepatic portosystemic shunt

\section{Authors' contributions}

$\mathrm{MV}$ and LA performed the procedure in emergency and the follow-up based on Colour Doppler. MV, CL, MC, AC, FP and FDC contributed to study design, manuscript preparation and revision. All authors read and approved the final manuscript.

\section{Funding}

The authors state that this work has not received any funding.

\section{Availability of data and materials}

Data and materials can be provided on request.

\section{Ethics approval and consent to participate}

The procedure in emergency was performed according to studies involving human participants and it was in accordance with the ethical standards of the institutional and/or national research committee and with the 1964 Helsinki Declaration and its later amendments or comparable ethical standards. The patient signed a specific institutional procedure-related consent form that covers retrospective observational studies.

\section{Consent for publication}

See "Ethics approval consent to participate" section.

\section{Competing interests}

The authors declare that they do not have competing interests.

\section{Author details}

'Department of Diagnostic and Interventional Radiology, Circolo Hospital, Viale Borri 57, 21100 Varese, Italy. Insubria University, Varese, Italy. ${ }^{3}$ Department of Clinical and Experimental Radiology, San Raffaele Scientific Institute, Milan, Italy. ${ }^{4}$ Department of Radiology, European Institute of Oncology, Milan, Italy. ${ }^{5}$ Vita-Salute San Raffaele University, Milan, Italy.

Received: 21 September 2020 Accepted: 13 November 2020 Published online: 10 December 2020

\section{References}

1. Loffroy R, Favelier S, Pottecher P et al (2015) Transjugular intrahepatic portosystemic shunt for acute variceal gastrointestinal bleeding: indications, techniques and outcomes. Diagn Interv Imaging 96:745-755. https://doi. org/10.1016/j.diii.2015.05.005

2. Fagiuoli S, Bruno R, Debernardi Venon W et al (2017) Consensus conference on TIPS management: techniques, indications, contraindications. Dig Liver Dis 49:121-137. https://doi.org/10.1016/j.dld.2016.10.011

3. Schulteib M, Giesler M, Maruschke L et al (2019) Adjuvant transjugular variceal occlusion at creation of a transjugular intrahepatic portosystemic shunt (TIPS): efficacy and risks of Bucrylate embolization. Cardiovasc Intervent Radiol 42:729-736. https://doi.org/10.1007/s00270-019-02176-y

4. Lakhoo J, Bui JT, Lokken RP, Ray CE Jr, Gaba RC (2016) Transjugular intrahepatic portosystemic shunt creation and variceal coil or plug embolization ineffectively attain gastric variceal decompression or occlusion: results of a 26-patient retrospective study. J Vasc Interv Radiol 27:10011011. https://doi.org/10.1016/j.jvir.2016.02.019

5. Sarwar A, Esparaz AM, Tapper EB et al (2017) Comparison of vascular plugs and pushable coils for variceal embolization After TIPS. AJR Am J Roentgenol 208:650-655. https://doi.org/10.2214/AJR.16.16012

6. Lee J, Lim JW, Cho YD (2018) Follow-up outcomes after re-embolization for recanalized aneurysms after initial coiling: further recurrence rates and related risk factors. World Neurosurg 114:e508-e517. https://doi.org/10. 1016/j.wneu.2018.03.017

7. Crowley RW, Ducruet AF, Kalani MY, Kim L, Albuquerque FC, Mc Dougall CG (2015) Neurological morbidity and mortality associated with the endovascular treatment of cerebral arteriovenous malformations before and during the Onyx era. J Neurosurg 122:1492-1497. https://doi.org/10.3171/ 2015.2.JNS131368

8. Lozupone E, Bracco S, Trombatore P et al (2020) Endovascular treatment of cerebral dural arteriovenous fistulas with Squid 12. Interv Neuroradiol 1591019920954095. https://doi.org/10.1177/1591019920954095

9. Chivot C, Bouzerar R, Yzet T, Reix T (2019) Transarterial perigraft balloonassisted Onyx embolization of type II endoleak. J Vasc Interv Radiol 30:617619. https://doi.org/10.1016/j.jvir.2018.11.030

10. Venturini M, Lanza C, Marra P et al (2019) Transcatheter embolization with Squid, combined with other embolic agents or alone, in different abdominal diseases: a single-center experience in 30 patients. CVIR Endovasc 2:8. https://doi.org/10.1186/s42155-019-0051-7

11. Venturini M, Marra P, Augello L et al (2020) Elective embolization of splenic artery aneurysms with an ethylene vinyl alcohol copolymer agent (Squid) and detachable coils. J Vasc Interv Radiol 31:1110-1117. https://doi.org/10 1016/j.jvir.2019.12.797

12. Venturini M, Della Corte A, Lanza C, Fontana F, Chiesa R, De Cobelli F (2020) Embolization of 2 coexisting intraparenchymal renal artery aneurysms with an ethylene vinyl alcohol copolymer agent (Squid) and coils. Cardiovasc Intervent Radiol 43:942-944. https://doi.org/10.1007/s00270-020-02458-w

13. Breguet R, Boudabbous S, Pupulim LF et al (2018) Ethylene vinyl alcohol copolymer for occlusion of specific portal branches during preoperative portal vein embolisation with n-butyl-cyanoacrylate. Eur Radiol 28:48104817. https://doi.org/10.1007/s00330-018-5476-1

14. Erbahceci Salik A, Islim F, Akgul A, Cil BE (2014) Concomitant transarterial and transvenous embolization of a pelvic arteriovenous malformation using a new liquid embolic agent, squid-12 and detachable coils. Case Rep Vasc Med 972870. https://doi.org/10.1155/2014/972870

15. Pop R, Mertz L, llyes A et al (2019) Beam hardening artifacts of liquid embolic agents: comparison between Squid and Onyx. J Neurointerv Surg 11:706-709. https://doi.org/10.1136/neurintsurg-2018-014542

16. Treitl KM, Scherr M, Forth M, Braun F, Maxien D, Treitl M (2015) Reduction of CT beam hardening artefacts of ethylene vinyl alcohol copolymer agent by 
variation of the tantalum content: evaluation in a standardized aortic endoleak phantom. Eur Radiol 25:597-605. https://doi.org/10.1007/s00330-014-3438-9

17. Bailey MA, McPherson SJ, Troxler MA, Peach AH, Patel JV, Scott DJ (2011) Ischemic skin ulceration complicating glue embolization of type II endoleak after endovascular aneurysm repair. J Vasc Interv Radiol 22:163-167. https:// doi.org/10.1016/j.jvir.2010.10.018

18. Namazi MH, Khaheshi I, Serati AR, Movahed MR (2016) The safety of using large amount (30 cc) of Onyx (Ethylene-vinyl Alcohol Copolymer) for the treatment of large type II endoleak after endovascular repair of abdominal aortic aneurysm. Int J Angiol 25:169-172. https://doi.org/10.1055/s-0036-1593826

19. Pamuk AG, Saatci I, Cekirge HS, Aypar U (2005) A contribution to the controversy over dimethyl sulfoxide toxicity: anesthesia monitoring results in patients treated with Onyx embolization for intracranial aneurysms. Neuroradiology 47:380-386. https://doi.org/10.1007/s00234-004-1323-y

\section{Publisher's Note}

Springer Nature remains neutral with regard to jurisdictional claims in published maps and institutional affiliations.

\section{Submit your manuscript to a SpringerOpen ${ }^{\circ}$ journal and benefit from:}

- Convenient online submission

- Rigorous peer review

- Open access: articles freely available online

High visibility within the field

- Retaining the copyright to your article

Submit your next manuscript at $\boldsymbol{\wedge}$ springeropen.com 